\title{
EXPERIMENTAL STUDY OF TRACHEAL ALLOTRANSPLANTATION WITH CRYOPRESERVED GRAFTS
}

Takahiro Mukaida, MD

Nobuyoshi Shimizu, MD

Motoi Aoe, MD

Akio Andou, MD

Hiroshi Date, MD

Kazunori Okabe, MD

Motohiro Yamashita, MD

Shingo Ichiba, MD

\begin{abstract}
Objective: Tracheal reconstruction is necessary in patients with extensive tracheal stenosis caused by neoplasm, trauma, and congenital disease. We investigated the possibility of tracheal allotransplantation with cryopreserved grafts in a canine model. Methods: A seven-ring section of thoracic trachea was removed in 19 adult mongrel dogs. In group A $(n=4)$, a five-ring tracheal autograft was implanted. In group B $(n=6)$, a five-ring allograft was implanted without immunosuppression. In group $C(n=9)$, a five-ring cryopreserved tracheal allograft was implanted without immunosuppression. Omentopexy wrapping around the grafts and both anastomotic sites was used in all animals. Results: All grafts survived without any evidence of atrophy or stenosis in group A. All animals in group B died of severe airway obstruction within 1 month, and postmortem examination of these grafts showed epithelial defect and necrotic tracheal cartilage in the scar tissue. In group $\mathrm{C}$, no animals died of asphyxia caused by severe stenosis of the grafts. The graft epithelium was no longer present 20 days after transplantation, and the graft was covered with regenerated epithelium within about 60 days after the operation. Conclusion: These findings show that cryopreserved tracheal allografts can be transplanted by means of omentopexy without immunosuppression and that cryopreservation may reduce tracheal allogenicity. (J Thorac Cardiovasc Surg 1998;116:262-6)
\end{abstract}

$T^{\mathrm{r}}$ racheal reconstruction is necessary in patients with extensive tracheal stenosis caused by neoplasm, trauma, and congenital disease. Experimentally, the reconstruction of a long defect of the thoracic trachea by allotransplantation has been reported to be possible with the aid of immunosuppressive agents and omentopexy. ${ }^{1}$ Date $^{2}$ previously reported that tracheal autografts could be preserved for up to 48 hours in Euro-Collins solution. However, a more long-term tracheal preservation period is necessary to solve the shortage of organ donors. We believe that tracheal cryopreservation is the best method for this, and we obtained satisfactory results in tracheal reconstruction with a cryopreserved allograft without immunosuppression.

From the Department of Surgery II, Okayama University Medical School, Okayama, Japan.

Received for publication May 2, 1997; revisions requested August 6, 1997; revisions received Feb. 12, 1998; accepted for publication March 23, 1998

Address for reprints: Takahiro Mukaida, MD, The Department of Surgery II, Okayama University Medical School, 2-5-1 Shikata-chou, Okayama, 700, Japan.

Copyright (c) 1998 by Mosby, Inc.

$0022-5223 / 98 \$ 5.00+0 \quad \mathbf{1 2} / \mathbf{1} / \mathbf{9 0 5 0 3}$

\section{Material and methods}

Experimental design. Nineteen adult mongrel dogs, weighing 8 to $16 \mathrm{~kg}$, were used. In group A (autotransplantation; $n=4$ ), a section of seven rings of thoracic trachea was removed and five rings of trachea were immediately reimplanted. In group B $(n=6)$, a section of the thoracic trachea of the same length was allotransplanted with five rings of trachea immediately after harvest. In group $C(n=9)$, allotransplantation was performed with grafts that had been cryopreserved for more than 20 days. Omentopexy was performed in all groups, and immunosuppressive agents and steroids were not used after the operation in any group.

Harvest of grafts. Each animal was anesthetized with intramuscular ketamine $(10 \mathrm{mg} / \mathrm{kg})$, intravenous sodium pentobarbital $(30 \mathrm{mg} / \mathrm{kg})$, and pancuronium bromide (2 mg).

The animals were orally intubated and connected to a volume-limited respirator (a tidal volume of $20 \mathrm{ml} / \mathrm{kg}$ and a frequency of 20 breaths/min). Anesthesia was maintained with $50 \%$ oxygen, $50 \%$ nitrous oxide, and $1 \%$ halothane. The animals were placed in the lateral decubitus position and the chest was opened via a right thoracotomy through the right fourth intercostal space. The thoracic trachea was dissected and seven tracheal rings were excised in continuity.

Cryopreservation. In group $\mathrm{C}$, the section of seven tracheal rings excised from the donor animal was immersed in a preservative solution at $4^{\circ} \mathrm{C}$ for 4 hours. The 
Table I. Results of tracheal autotransplantation

\begin{tabular}{|c|c|c|c|c|}
\hline $\begin{array}{l}\text { Dog } \\
\text { No. }\end{array}$ & $\begin{array}{l}\text { Time } \\
\text { (days) }\end{array}$ & Outcome & Graft status & Cause of death \\
\hline 1 & 7 & Put to death & Viable & \\
\hline 2 & 50 & Put to death & Viable & \\
\hline 3 & 123 & Put to death & Viable & \\
\hline 4 & 335 & Died & Viable & Diarrhea \\
\hline
\end{tabular}

preservation solution consisted of Dulbecco's modified Eagle's medium (Gibco, Grand Island Biological Company, New York, N.Y.), $20 \%$ fetal calf serum, $10 \%$ dimethyl sulfoxide, and a $0.1 \mathrm{~mol} / \mathrm{L}$ concentration of sucrose. A CELL FREEZE bag (7039-2, CharterMed Inc., Lakewood, N.J.) containing the trachea was filled with the preservative solution and sealed. The bag was surrounded with cotton, placed in a plastic case, and the case was frozen at $-80^{\circ} \mathrm{C}$ for 24 hours. The bag was then stored in gaseous liquid nitrogen $\left(-196^{\circ} \mathrm{C}\right)$ for 20 more days. The cryopreserved trachea was thawed rapidly in a water bath maintained at $37^{\circ} \mathrm{C}$ before transplantation.

Transplantation procedure. Recipient dogs were anesthetized in the same way as donor animals. Animals were placed in the left semidecubitus position, and a right thoracotomy was performed. After the azygos vein was ligated and transected, the thoracic trachea was isolated and seven tracheal rings were removed. Tracheal continuity was restored by insertion of the tracheal graft with five rings and over-and-over continuous 4-0 Prolene suture (Ethicon, Inc., Somerville, N.J.). The grafts were sutured by the telescopic method so that both the central and peripheral portions could be positioned correctly. After completion of the anastomoses, the omental pedicle was brought into the right hemithorax through an incision in the right hemidiaphragm and wrapped around the graft, including both anastomotic sites.

Postoperative follow-up. Postoperatively, animals received intramuscular antibiotics for the first 3 days. No immunosuppressive agents or steroids were given. Follow-up bronchoscopic studies were performed weekly for a month to examine graft viability. When animals died or were put to death, the transplanted graft and three rings of recipient trachea from the anastomotic site were excised in continuity and examined grossly and microscopically.

All animals received humane care in compliance with the "Principles of Laboratory Animal Care" formulated by the National Society for Medical Research and the "Guide for the Care and Use of Laboratory Animals" prepared by the Institute of Laboratory Animal Resources and published by the National Institutes of Health (NIH publication No. 86-23, revised 1985).

\section{Results}

In group A (Table I), three animals were put to death on days 7, 50, and 123 after transplantation and one died of prostration caused by diarrhea on day 335. That dog survived the longest of any of the
Table II. Results of tracheal allotransplantation (group B)

\begin{tabular}{cccll}
\hline $\begin{array}{c}\text { Dog } \\
\text { No. }\end{array}$ & $\begin{array}{c}\text { Time } \\
\text { (days) }\end{array}$ & Outcome & \multicolumn{1}{c}{ Graft status } & Cause of death \\
\hline 1 & 7 & Put to death & Viable & \\
2 & 15 & Died & Partial necrosis & Prostration \\
3 & 20 & Died & Necrosis & Asphyxia \\
4 & 24 & Died & Necrosis & Asphyxia \\
5 & 25 & Died & Necrosis & Asphyxia \\
6 & 28 & Died & Necrosis & Asphyxia \\
\hline
\end{tabular}

study animals. All four autografts, however, proved to be viable, with almost normal tracheal structure, and were free of granulation tissue or a stricture (Fig. 1, A). Histologic examination showed pseudostratified columnar ciliary epithelium, viable subepithelial tissue, and normal cartilage (Fig. 1, B).

In group B (Table II), four animals died of asphyxia within 1 month because of severe stenosis of the airway caused by extreme shrinkage of the grafts (Fig. 2, A). Histologic examination revealed epithelial defects, granulation tissue with fibrosis, mononuclear cell infiltration into the subepithelium, and absorption of tracheal cartilage (Fig. 2, B). One animal was put to death on day 7 after transplantation, and its allograft showed relatively normal appearing ciliary epithelium, normal subepithelial tissue, and normally shaped cartilage without cell infiltration. The allograft taken from one animal that died of prostration 15 days after the operation showed degeneration and necrosis of the tracheal epithelium and cartilage.

In group C (Table III), no animal died of asphyxia due to severe stenosis of the airway caused by extreme shrinkage of the graft. The follow-up after transplantation was from 10 to 206 days. Four animals were put to death, three died of other complications, and two remain alive. The causes of death were prostration resulting from continuous diarrhea and anorexia in two dogs and respiratory failure owing to pneumonia in one. The allograft taken from one animal killed 10 days after the operation $(\operatorname{dog} 8)$ appeared almost normal. The epithelium had histologically pseudostratified columnar features without cilia, but subepithelial tissue was viable and the cartilage maintained its shape. The allografts from animals that were killed or that died in less than 30 days after the operation (dogs 4, 5, and 6) had no epithelium histologically, but mononuclear cell infiltration was limited and viability of the tracheal cartilage and the subepithelial 

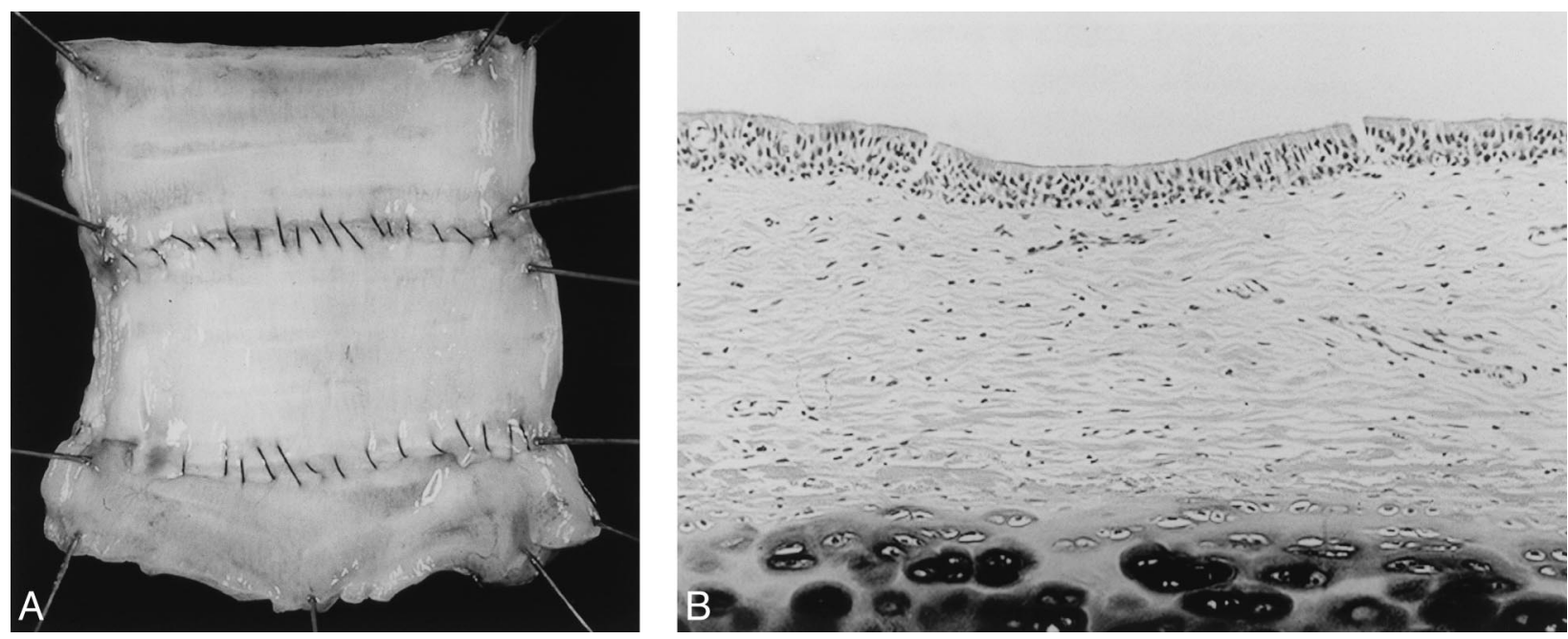

Fig. 1. A, Gross examination shows good graft acceptance. No stenosis or signs of necrosis are seen in the graft. B, Histologic examination shows pseudostratified columnar ciliary epithelium, viable subepithelial tissue, and normal cartilage. (Hematoxylin-eosin stain; original magnification $\times 100$.)

Table III. Results of tracheal allotransplantation with cryopreserved graft (group C)

\begin{tabular}{cccccc}
\hline $\begin{array}{c}\text { Dog } \\
\text { No. }\end{array}$ & $\begin{array}{c}\text { Time } \\
\text { (days) }\end{array}$ & Outcome & $\begin{array}{c}\text { Graft } \\
\text { status }\end{array}$ & $\begin{array}{c}\text { Cause } \\
\text { of } \\
\text { death }\end{array}$ & $\begin{array}{c}\text { Preservation } \\
\text { time } \\
\text { (days) }\end{array}$ \\
\hline 1 & 53 & Put to death & Viable & & 14 \\
2 & 46 & Put to death & Viable & & 21 \\
3 & 206 & Alive & Viable & & 150 \\
4 & 20 & Put to death & Viable & & 76 \\
5 & 26 & Died & Viable & Pneumonia & 34 \\
6 & 27 & Died & Viable & Prostration & 34 \\
7 & 70 & Died & Viable & Prostration & 20 \\
8 & 10 & Put to death & Viable & & 80 \\
9 & 58 & Alive & Viable & & 133 \\
\hline
\end{tabular}

tissue was preserved. The allografts from animals put to death 46 and 53 days after the operation (dogs 1 and 2) showed partially defective epithelium. Pseudostratified columnar ciliary epithelium was observed near the anastomotic site, but one epithelial layer without cilia was present next to an epithelial defect. Neither mononuclear cell infiltration nor resorption of tracheal cartilage was observed. The grafts taken from the animal that survived more than 70 days $(\operatorname{dog} 7)$ showed normal tracheal architecture (Fig. 3, $A$ ). Histologic examination revealed that the mucosa was composed of pseudostratified columnar ciliary epithelium and the tracheal secretory glands were regenerated. The cartilaginous matrix was intact, the cells were viable in the lacunae of the carti- lage, and infiltration by mononuclear cells was not observed (Fig. 3, B). In all cryopreserved allografts, however, cartilage segments showed the loss of chondrocyte nuclei in the lacunae and poor staining reaction of the lacunae.

\section{Discussion}

Many experiments have been performed to reconstruct tracheal defects by transplantation and to examine donor tracheal preservation. Previous experiments in our laboratory showed satisfactory results with the use of omentopexy and immunosuppression for tracheal allotransplantation $^{1}$ and also showed that tracheal autografts could be preserved for up to 48 hours in EuroCollins solution. ${ }^{2}$ Before tracheal transplantation can be applied clinically, however, the problem of the shortage of organ donors must be solved. A more long-term preservation of trachea will be necessary to help accomplish this. Cryopreservation has been shown to be a useful technique for storing isolated organs, and cryopreservation of cardiac valves and cartilage has already had clinical success. ${ }^{3,4}$ Histologic examination of cryopreserved canine tracheal tissue has shown normal epithelium, smooth muscle, and ciliary function. ${ }^{5}$ A long tracheal defect that incorporates $50 \%$ of the tracheal circumference can be repaired with a cryopreserved cartilaginous allograft, ${ }^{6}$ and it is possible to autotransplant trachea cryopreserved in a preservative solution containing trehalose. ${ }^{7}$ 

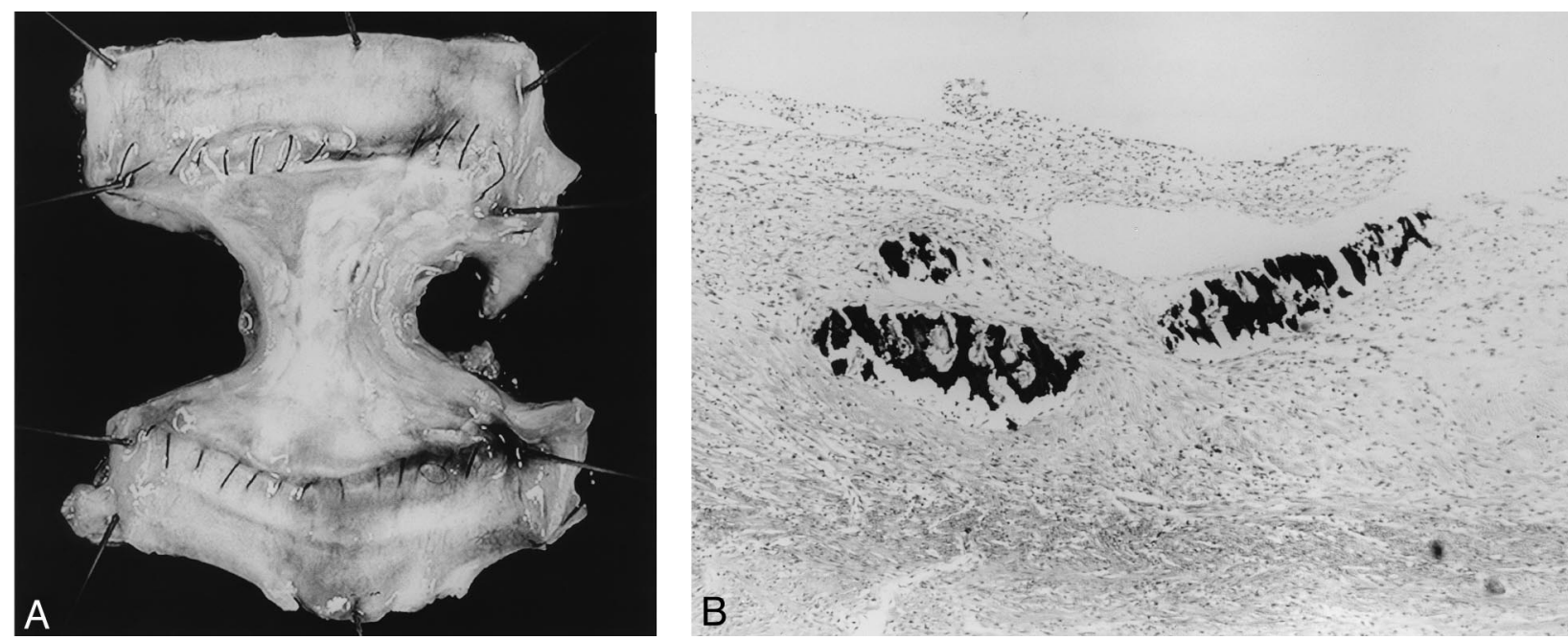

Fig. 2. A, The graft shows the severe stenosis caused by extreme shrinkage. B, Histologic examination reveals defective epithelium and necrotic tracheal cartilage in the scar tissue. (Hematoxylin-eosin stain; original magnification $\times 100$.)
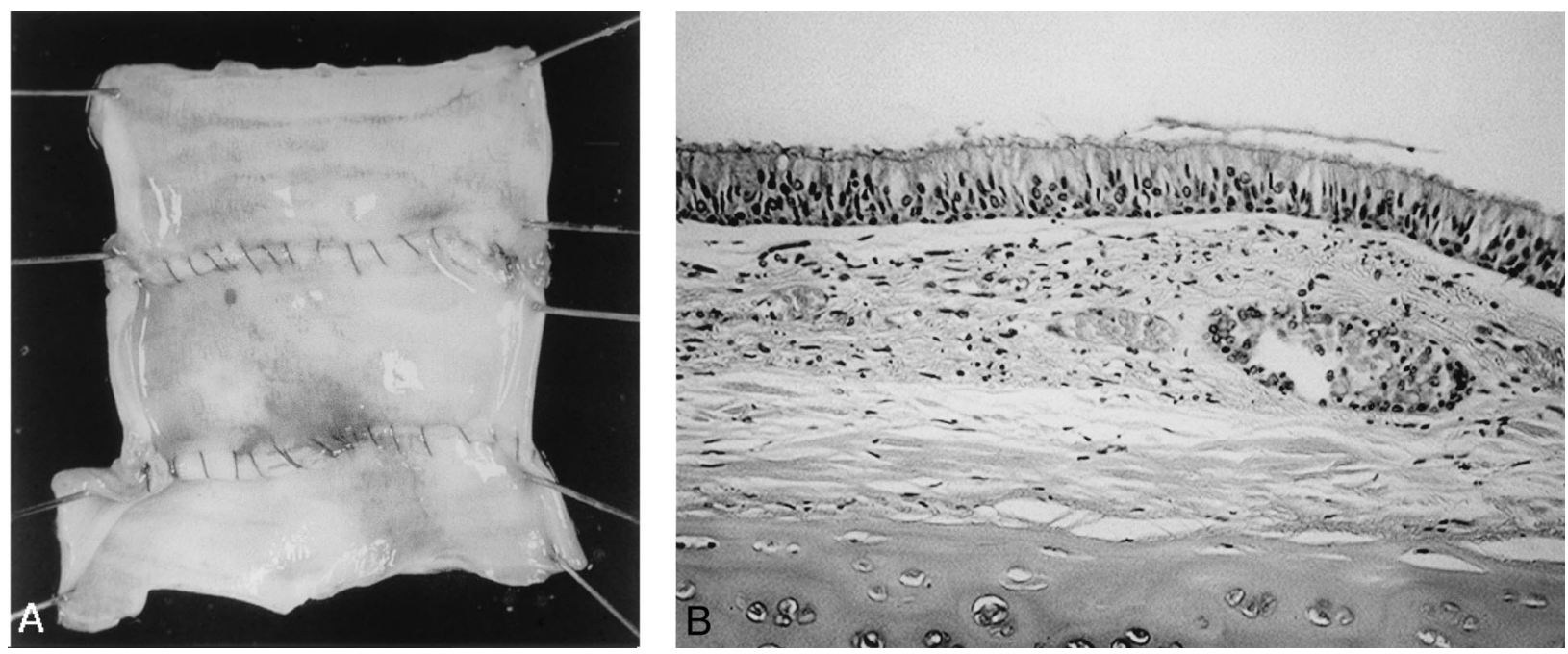

Fig. 3. A, Gross examination shows normal tracheal architecture as seen in Fig. $1, A$. No stenosis of the graft is seen. B, Histologic examination shows that the mucosa is composed of pseudostratified columnar ciliary epithelium and regeneration of the tracheal secretory glands. The cartilaginous matrix is intact, and the cells are viable in the lacunae of the cartilage. (Hematoxylin-eosin stain; original magnification $\times 100$.)

The application of these techniques to tracheal allotransplantation seems logical.

Kawabe and Yoshinao ${ }^{8}$ showed a difference in the survival of chondrocytes by changing the concentration and time of exposure to dimethyl sulfoxide. They concluded that the best technique used is $10 \%$ dimethyl sulfoxide and an exposure at $4^{\circ} \mathrm{C}$ for 4 hours. In the present study, the tracheal grafts were exposed to $10 \%$ dimethyl sulfoxide at $4^{\circ} \mathrm{C}$ for 4 hours before cryopreservation.

In the present study, cryopreserved tracheal allografts survived with no evidence of stenosis, and they remained sufficiently rigid to keep the lumen completely open. The subepithelial tissue and the tracheal cartilage were viable histologically in all cryopreserved tracheal allografts. Although three 
animals died of other complications in group $\mathrm{C}$, the causes of these deaths are not related to problems with the allografts. The allograft epithelium is no longer present 20 days after transplantation and is gradually regenerated from the anastomotic site at the recipient trachea. The allograft was covered with regenerated epithelium within about 60 days after the operation. We believe the origin of the regenerated epithelium in the cryopreserved allograft is from the recipient tracheal epithelium, which we are studying by genetic methods in our laboratory.

In the present study, animals undergoing tracheal allotransplantation with cryopreserved grafts did not need immunosuppressive agents after the operation, which suggests that tracheal transplantation can be extended to tracheal stenosis caused not only by benign disease, trauma, or congenital disease, but also by a malignant neoplasm. However, the antigenicity of tracheal transplants is not completely known. Gertzbein and associates ${ }^{9}$ suggested that chondrocytes have tissue-specific antigen on their surfaces and that these cells are surrounded by a weakly antigenic matrix that acts as a biologic barrier to protect the chondrocytes. Bujia and associates ${ }^{10}$ demonstrated HLA class II subregion gene products on human tracheal epithelium and mixed glandular tissue; they concluded that tracheal mucosa may be the major antigenic structure of the trachea and may be responsible for the immunogenic action of tracheal allotransplants. The present study showed a loss of chondrocyte nuclei and the poor staining reaction in the matrix after cryopreservation. It also showed that the epithelium of the cryopreserved allograft was no longer present after transplantation. These facts may be relevant to the decrease of cryopreserved allograft antige- nicity, or cryopreservation itself may decrease the antigenicity of the trachea.

We conclude that cryopreserved tracheal allograft can be transplanted by means of omentopexy without immunosuppression. We believe, however, that more long-term follow-up is necessary to determine the possibility of progressive rejection. Further investigation of antigenicity is also necessary before our method can be applied clinically.

\section{REFERENCES}

1. Moriyama S, Shimizu N, Teramoto S. Experimental tracheal allotransplantation using omentopexy. Transplant Proc 1986; 21:2596-600.

2. Date M. Experimental studies on canine tracheal preservation. J Jpn Surg Soc 1990;91:1740-8.

3. Kirklin JK, Smith D, Novick W, Naftel DC, Kirklin JW, Pacifico AD, et al. Long-term function of cryopreserved aortic homografts: a ten-year study. J Thorac Cardiovasc Surg 1993;106:154-66.

4. Hartog JM, Slavin AB, Kline SN. Reconstruction of the temporomandibular joint with cryopreserved cartilage and freeze-dried dura: a preliminary report. J Oral Maxillofac Surg 1990;48:919-25.

5. Deschamps C, Trastek VF, Ferguson JL, Martin WJ, Colby TV, Pairolero PC, et al. Cryopreservation of canine trachea: functional and histological change. Ann Thorac Surg 1989; 47:208-12.

6. Messineo A, Filler RM, Bacoric A, Smith CR. Repair of long tracheal defects with cryopreserved cartilaginous allografts. J Pediatr Surg 1992;27:1131-5.

7. Yokomise H, Inui K, Wada H, Hasegawa S, Ohno N, Hitomi $\mathrm{S}$. Reliable cryopreservation of trachea for one month in a new trehalose solution. J Thorac Cardiovasc Surg 1995;110: 382-5.

8. Kawabe N, Yoshinao M. Cryopreservation of pig trachea. Int Orthop 1990;14:231-5.

9. Gertzbein SD, Tait JH, Devlin SR, et al. The antigenicity of chondrocytes. Immunology 1997;33:141-5.

10. Bujia J, Wilmes E, Hammer C, Kastenbauer E. Tracheal transplantation: demonstration of HLA class II subregion gene products on human trachea. Acta Otolaryngol 1990;110: $179-84$.

\section{Bound volumes available to subscribers}

Bound volumes of The Journal of Thoracic and Cardiovascular Surgery are available to subscribers (only) for the 1998 issues from the Publisher, at a cost of $\$ 122.00$ for domestic, $\$ 151.94$ for Canadian, and $\$ 142.00$ for international subscribers for Vol. 115 (January-June) and Vol. 116 (July-December). Shipping charges are included. Each bound volume contains a subject and author index and all advertising is removed. Copies are shipped within 60 days after publication of the last issue of the volume. The binding is durable buckram with the Journal name, volume number, and year stamped in gold on the spine. Payment must accompany all orders. Contact Mosby, Inc., Subscription Services, 11830 Westline Industrial Drive, St. Louis, Missouri 63146-3318, USA; phone $800-453-4351$ or 314-453-4351.

Subscriptions must be in force to qualify. Bound volumes are not available in place of a regular Journal subscription. 